Supplementary Information for

\title{
Investigation of New Particle Formation mechanisms and aerosol processes at the
}

\author{
Marambio Station, Antarctic Peninsula.
}

\section{SI 1 Instrument description}

\section{Measuring real time gas-phase aerosol precursors}

The Atmospheric Pressure interface Time Of Flight (APi-TOF) mass spectrometer (TOFWERK A.G.) enables the analysis of the chemical composition of gas-phase atmospheric ions (Junninen et al., 2010) and neutral molecules that can be charged or clustered with nitrate, $\mathrm{NO}_{3}{ }^{-}$, ions (Jokinen et al., 2012). The latter when complied to a chemical ionization source. The APi-TOF was run most of the time with an Eisele-type chemical ionization inlet (Aerodyne / University of Helsinki - Eisele and Tanner (1993)) using nitric acid, $\mathrm{HNO}_{3}$, as reagent for chemical ionization (CI, Jokinen et al., 2012). The instrument constantly sampled outside air via a one-meter-long stainless-steel inlet tube, with a diameter of $3 / 4 \mathrm{inch}$, actively heated $\left(>5^{\circ} \mathrm{C}\right)$, insulated and with a U-shaped bend at its extremity, avoiding freezing or sampling of dust or snowflakes. The sample flow was kept constant at $10 \mathrm{~L} \mathrm{~min}^{-1}$ with a total vacuum flow of $\sim 30 \mathrm{~L} \mathrm{~min}^{-1}$ and a pressurized sheath air flow (pumped from filtered outside air) of $\sim 20 \mathrm{~L} \mathrm{~min}^{-1}$. The sheath air flow contained the saturated nitric acid vapor $\left(\sim 3 \mathrm{~mL} \mathrm{~min}^{-1}\right)$ later ionized to nitrate ions and their associated multimers (i.e., $\mathrm{NO}_{3}^{-}, \mathrm{HNO}_{3} \mathrm{NO}_{3},\left(\mathrm{HNO}_{3}\right)_{2} \mathrm{NO}_{3}$ ) after X-ray exposure. After entering the instrument via a $300 \mu \mathrm{m}$ critical orifice, the sampled molecules - as atmospheric molecules clustered with nitrates ions - were guided into the TOF analyzer $\left(\sim 3.5 \times 10^{-6} \mathrm{mbar}\right)$ through a succession of chambers. The instrument chambers were at different pressure and monitored at all times: two segmented quadrupole chambers $\left(\sim 1.5 \mathrm{mbar}\right.$ and $\sim 10^{-2} \mathrm{mbar}$, respectively), and an ion lens assembly $\left(\sim 10^{-5} \mathrm{mbar}\right)$. Inside the TOF analyzer, ions are separated according to their mass to charge ratio $(\mathrm{m} / \mathrm{z})$. The exact elemental composition of ambient molecules is based on the mass defect of individual recorded signal peaks and can be calculated by combining the individual exact masses of the possible atoms present in the ion cluster. Additionally, an estimated ion concentration can be calculated by normalizing the signal of the detected peaks of interest by the sum of reagent ion signals and by applying a calibration factor. In this work, we estimate a calibration factor of $5 \times 10^{9}$ molecules $\mathrm{cm}^{-3}$, which is based on Sulfuric acid calibration that was performed ahead of the campaign. More information about the CI-APi-TOF instrumentation and the derived qualitative and quantitative products can be found in Jokinen et al. (2012).

To ensure an efficient ionization via proton transfer reaction between the sampled molecules and nitrate ion, we monitored of the total ion counts (TIC) and the respective signal of all nitrate ions (i.e., $\mathrm{NO}_{3}{ }^{-}, \mathrm{HNO}_{3} \mathrm{NO}_{3}{ }^{-}$ and $\left.\left(\mathrm{HNO}_{3}\right)_{2} \mathrm{NO}_{3}\right)^{-}$. The time series of the reagent ion signals can be found in Figure S1. In some instance, spikes of signal loss due to occasional power disturbances or exceptional failure of the pumping system were seen. Therefore, data filtering of measurements having a variation of more than $30 \%$ of the overall median of the TIC signal was applied. 

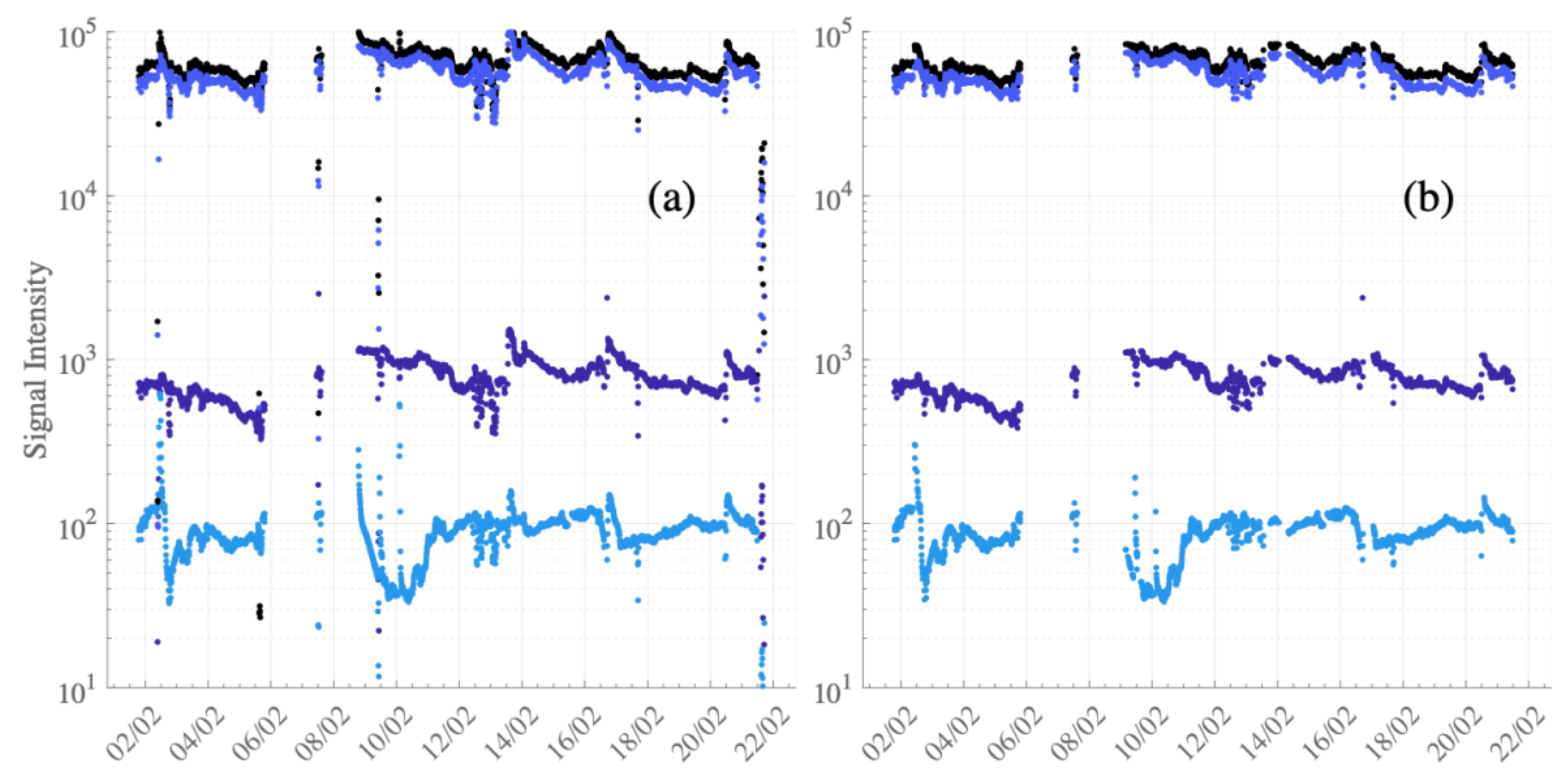

Figure S1: Time series of individual signal of reagent ions $\left(\mathrm{NO}_{3}{ }^{-}\right.$, dark-blue line; $\mathrm{HNO}_{3} \mathrm{NO}_{3}{ }^{-}$, medium-blue line; $\left(\mathrm{HNO}_{3}\right)_{2} \mathrm{NO}_{3}{ }^{-}$, lightblue line) and total ion count signal (TIC, dashed-black line) for raw data (a) and filtered data (b) - within $30 \%$ of total average TIC campaign. Unit mass resolution signal on 10 min average time (Standard local time, UTC -3).

A mass spectrum averaged between 15:30 and 16:30, on 16 February, with a mass range between 30 and 1000 Th is shown in Figure S2. A total of 465 peaks were fitted as most abundant high resolutions masses. Despite the high number of Fluor-containing peak found (identified to originate from the set-up tubing), we found a significant number of peaks - non attributed to Sulfuric acid, Methane sulfonic acid nor Iodic acid with positive mass defect. Those peaks were found to have differing masses than the traditional highly oxidized organic molecules, HOMs, as defined by Bianchi et al. (2019) and commonly measured in mid-latitudes (Ehn et al., 2014). Here, we estimated the upper limit for maximum accumulated possible HOM concentration being $2.3 \times 10^{7}$ molec. $\mathrm{cm}^{-3}$, assuming that peaks with mass-to-charge ratio larger than $200 \mathrm{Th}$ and with positive mass defect could be signals of (highly) oxidized organic compounds present in the Antarctic field. Considering our background measurements, some of these peaks were seen with even higher intensities, thus reducing the maximum HOM estimate to $1.61 \times 10^{7}$ molec.cm ${ }^{-3}, 1.26 \times 10^{7}$ molec. $\mathrm{cm}^{-3}$ or $1.92 \times 10^{7}$ molec.cm ${ }^{-3}$ accounting for an interpolated, the closest or an averaged background spectrum, respectively. Additionally, this estimate fall to $5.52 \times 10^{6}$ molec. $\mathrm{cm}^{-3}, 5.12 \times 10^{6}$ molec. $\mathrm{cm}^{-3}$, and $8.55 \times 10^{6} \mathrm{molec} \mathrm{cm}^{-3}$, respectively, when performing a removal of the background selection. Since no unambiguous chemical composition was found for those peaks, it is likely that only a fraction of those signals would contribute to possible HOM, if at all belonging to organics and/or oxidized molecule groups. 

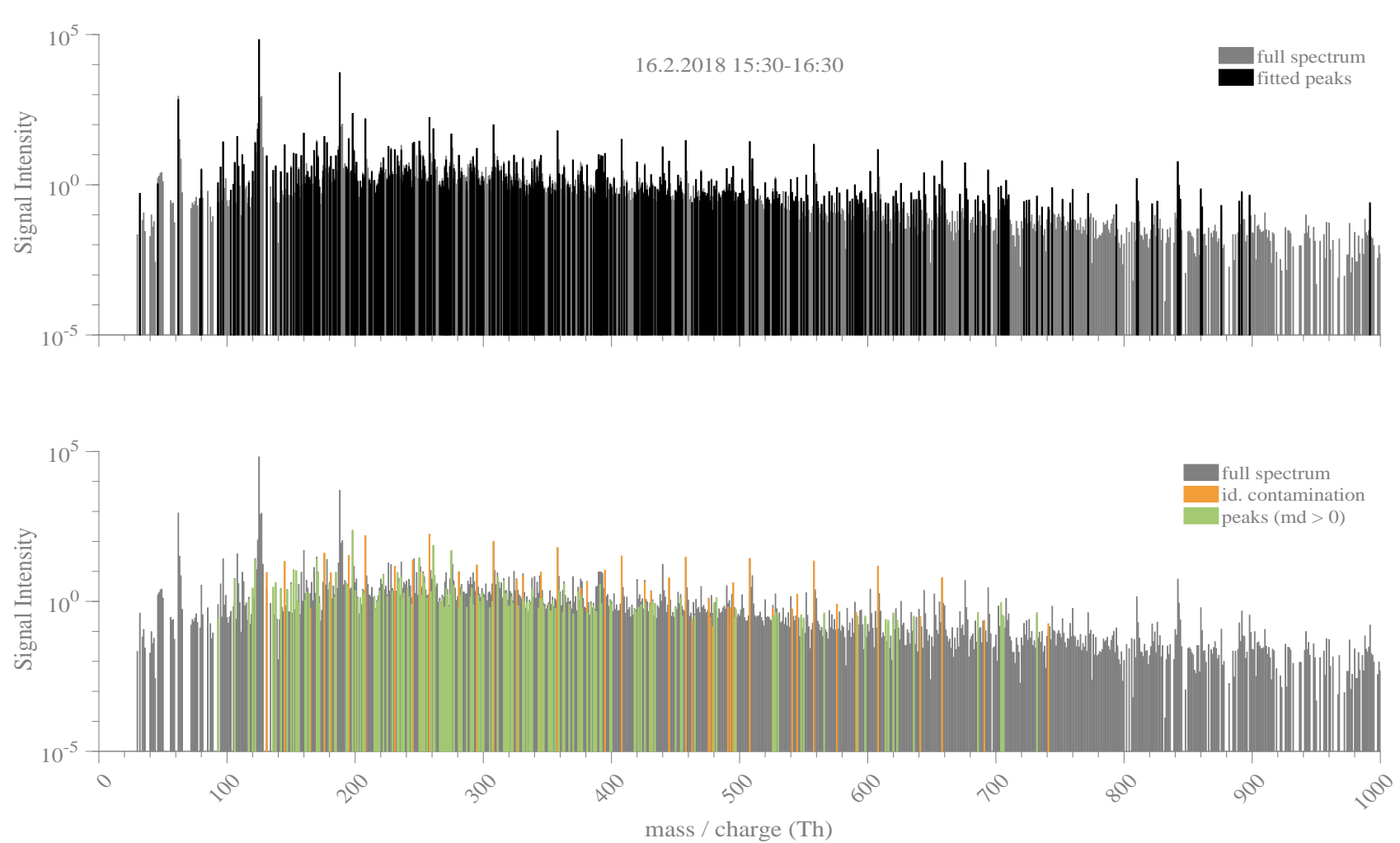

Figure S2: Mass spectra for 16 February showing the raw signal intensity (counts) as per mass-to-charge ratio withing the range 30 1000 Th. Upper panel: a total of 465 peaks - in black- were used for High resolution analysis (as most abundant peaks) among the full spectrum (grey). Lower panel: highlight on the identified contaminants (mostly Fluor-containing compounds, in orange) and possible organic oxidized compound (unresolved chemical composition, in green). Spectra averaged for 1 hour during new particle formation event.

In some instances, the X-ray ionizer was turned off, disabling the formation of artificial nitrate ions and thus the chemical ionization. In this mode, the mass spectrometer only measured naturally charged ions, either in negative, or exceptionally once in positive, ion mode. A timetable of the ion mode measurement periods is shown in Table S1. The main manuscript shows only negative ion mode data for 16 February.

Table S1: Timetable for (APi) ambient ion mode measurement. Note that the rest of the time the instrument measured in Chemical Ionization mode using Nitrate as reagent ion.

\begin{tabular}{|c|c|c|}
\hline Date & Start Time * (hh.ss) & Stop Time * (hh.ss) \\
\hline \multicolumn{3}{|c|}{$A P i$ - negative ion mode } \\
\hline 6 Feb. 2018 & 10.54 & 11.55 \\
\hline 6 Feb. 2018 & 14.57 & 15.59 \\
\hline 7 Feb. 2018 & 12.42 & 13.47 \\
\hline 8 Feb. 2018 & 14.32 & 15.34 \\
\hline 12 Feb. 2018 & 10.09 & 11.09 \\
\hline 13 Feb. 2018 & 12.03 & 13.04 \\
\hline 16 Feb. 2018 & 14.52 & 15.53 \\
\hline 21-23 Feb. 2018 & 17.11 & $14.33(+2 * *)$ \\
\hline \multicolumn{3}{|c|}{$A P i$ - positive ion mode } \\
\hline 16 Feb. 2018 & 15.59 & 17.00 \\
\hline
\end{tabular}




\section{Measuring aerosol particle (and ions) from nano- to micro-meter size}

\section{Nano Condensation Nucleus Counter ( $n C N C)$}

The smallest particles were measured via an assembly of a Particle Size Magnifier (PSM, Airmodus Ltd.) coupled to a Condensation Particle Counter (CPC, Airmodus Ltd.), together constituting a nano-Condensation Nucleus Counter (nCNC, Airmodus Ltd). The nCNC was operated in scanning mode, where the aerosol supersaturation is constantly modified. As a result, the size distribution of particles from $1.2 \mathrm{~nm}$ to $3 \mathrm{~nm}$ was obtained in various size bin with a resolution of 1 second per datapoint and $2 \times 120$ s per size bin during the scanning (upward and downward). The outside air was sampled into the $6 \mathrm{~mm}$ inlet of the PSM, as core sampling, via an $80 \mathrm{~cm}$ long insulated stainless-steel tube of $10 \mathrm{~mm}$ in diameter which was slightly bended at $45^{\circ}$. The nanometer-size particles contained in the $2.5 \mathrm{~L} \mathrm{~min}^{-1}$ sample flow entering the PSM undergo a first stage of growth by condensation of di-ethylene glycol vapors to reach sufficient diameter to be grown and detected by the CPC. The second stage of growth occurs via condensation of butanol vapors inside the CPC, where the particles are finally counted by optical detection. The CPC sample flow was $1 \mathrm{~L} \mathrm{~min}^{-1}$, and the excess flow was 1.5 $\mathrm{L} \mathrm{min}^{-1}$. More details about the PSM and the $\mathrm{nCNC}$ can be found in Vanhanen et al. (2011) and in Kangasluoma et al. (2016). In order to convert the data from the saturator flow rate to particle number size distribution, the Kernel inversion method was followed as well as inlet line losses corrections (Chan et al., 2020; Lehtipalo et al., 2014).

\section{Neutral Cluster and Air Ion Spectrometer (NAIS)}

The size distribution of total atmospheric particles and naturally charged ion clusters from 2.7 to $42 \mathrm{~nm}$ and from 0.8 to $42 \mathrm{~nm}$, respectively, was monitored using a Neutral Cluster and Air Ion Spectrometer (Airel Ltd.). The inlet (length: $90 \mathrm{~cm}$, diameter: $1 \mathrm{inch}$ ) was actively heated and bended as a U-shape to avoid dust, ice or snow to enter during the sampling of the $60 \mathrm{~L} \mathrm{~min}^{-1}$ flow rates of the outside air. In essence, the instrument is composed of two separated differential mobility analyzers (DMA) measuring simultaneously the electrical mobility of positively and negatively charged particles (as ion clusters). In front of each DMA, a preconditioning unit is equipped with a unipolar corona charger and an electrical filter. For neutral particle measurements, the unipolar charger was used to create a known aerosol charge distribution that then allowed to calculate the total particle numbers from the measured number of ions. Measurements were done in both ion and particle mode. Each mode was measured for $4 \mathrm{~s}$ and the offset signal was automatically removed from the measured signal to extract the ion concentrations. Mirme and Mirme (2013) and Manninen et al. (2016) explain the working principle and the measurement of the instrument in detail. The data are inverted from electric mobility diameter to aerodynamic diameter using the instrument specific inverter and later corrected for sampling losses.

\section{Differential Particle sizer (DMPS)}

With the sample and sheath flow rate of $1 \mathrm{~L} \mathrm{~min}^{-1}$ and $5 \mathrm{~L} \mathrm{~min}^{-1}$, respectively, a complete particle mobility distribution is obtained in 6 minutes. The size distribution is calculated from these raw data using an inversion routine, based on essentially the transfer function by Stolzenburg and McMurry (1991) and the multiple charging correction by Wiedensohler (1988). DMPS system design and data inversion routines are similar as described in Wiedensohler et al. (2012), for the 'Helsinki DMPS'.

The air sample is drawn into the DMPS via a shared laboratory inlet, already described in Asmi et al. (2018). The inlet consists of a stainless-steel tube (diameter: $16 \mathrm{~mm}$ ) extending to a height of $6 \mathrm{~m}$ above the ground and $2 \mathrm{~m}$ above the roof of the laboratory container. The inlet is equipped with a Digitel Enviro-sense $\mathrm{PM}_{10}$ particle pre-separator with a nominal flow rate of $2.3 \mathrm{~m}^{3} \mathrm{~h}^{-1}$. This flow is distributed to different instruments via a custom-made flow-divider unit designed for isokinetic sampling with minimal particle losses. The diffusional particle losses in the $2 \mathrm{~m}$-sample lines having a flow rate of $1 \mathrm{~L} \mathrm{~min}^{-1}$ are considered in the analysis.

Time series of DMPS data were flagged as good (000), possibly contaminated based on wind direction (189) or speed (188), instrument malfunction (699) and unidentified pollution (559), following the NILU EBAS database standards (https://projects.nilu.no/ccc/flags/flags.html, last access: 02 November, 2021) and with wind criteria as described by Asmi et al. (2018). 


\section{SI 2 Observation of NPF at Marambio Station}

Daily size distributions for individual events

Daily plots, including size distributions from $2.7 \mathrm{~nm}$ to $40 \mathrm{~nm}$ from the NAIS measurement, are shown in Figure S3 to identify and characterize each event individually.
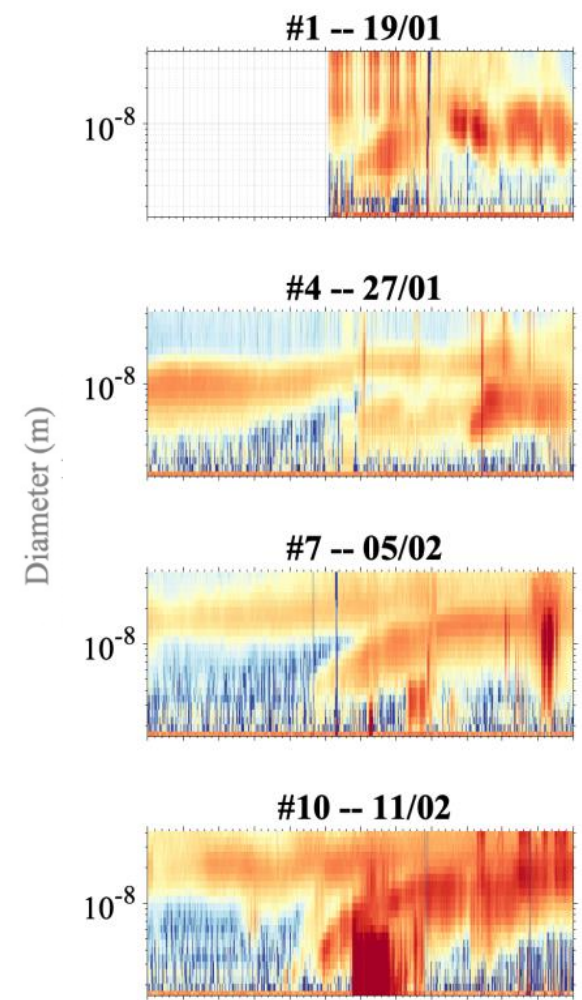

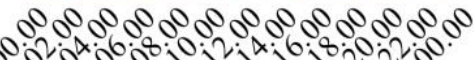

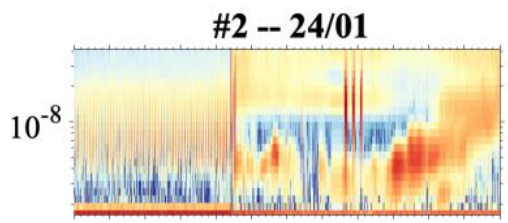

\#5 -- 28/01
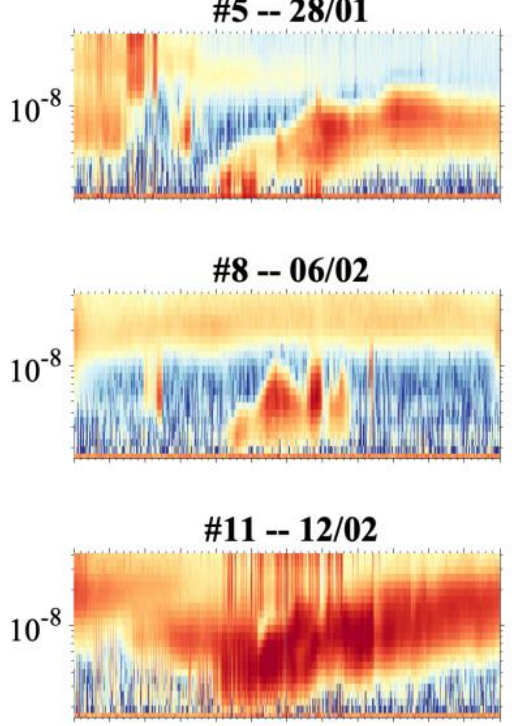

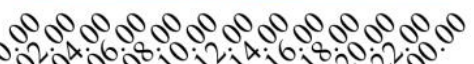
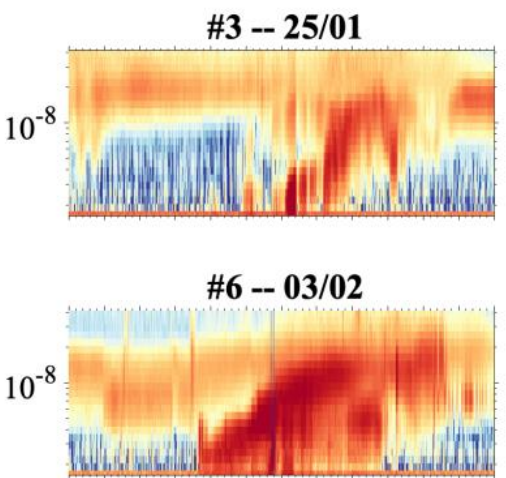

\#9 -- 10/02

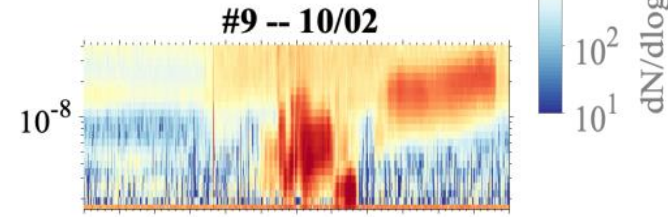

\#12 -- 16/02

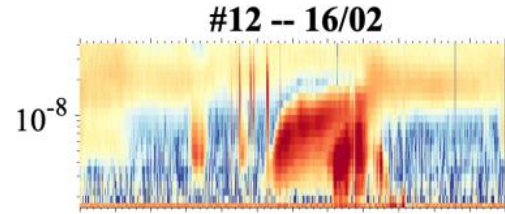

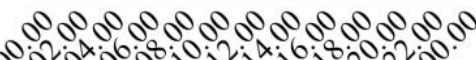

Figure S3: Daily size distribution of aerosol particle from NAIS measurements ( $2.7 \mathrm{~nm}$ to $42 \mathrm{~nm}$ ) for event days. Note that the data do not include the pollution flag.

Atmospheric air ions

Using NAIS instrumentation, neutral aerosol particles (cf. Fig. 2) but also naturally charged ion clusters can be detected. Size distribution series are shown below in Figure S4, for the particle (Fig. S4a) and ion mode (both positive negative and positive - Fig. S4b-c) of the NAIS, respectively. Note that the ion data are used in the estimation of formation rates for both positive and negative ion clusters presented in Table 1 in the manuscript. 

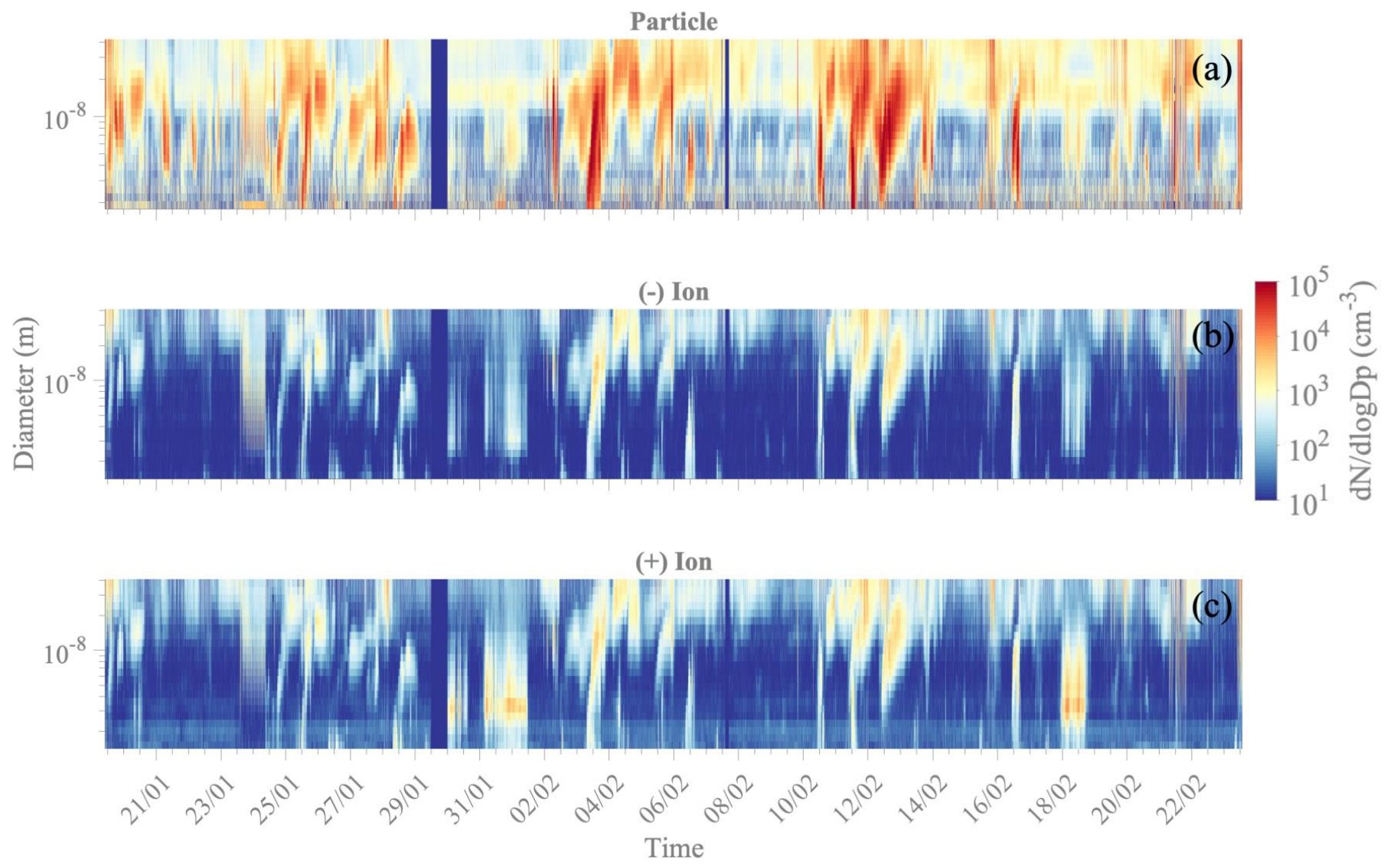

Figure S4: Size distribution of air ions from NAIS measurements during the whole campaign. The upper panel (a) shows the particle mode size distribution, the middle and lower panels are the ion mode size distribution for negative, and positive ion, respectively.

\section{SI 3 Sources of Aerosol precursors}

\section{Air mass trajectories}

Air mass backward trajectories were calculated with the NOAA HYSPLIT_4 model using the meteorological model data of the global data assimilation model (GDAS) half-degree archive (available between September 2007 - June 2019). Trajectories were calculated for the arrival height of $200 \mathrm{~m}$ above the ground level, which in Marambio island is about $200 \mathrm{~m}$ above the sea surface. One trajectory of 120-hours backward was calculated for every NPF event start time using the closest full hour, 13 trajectories in total. Trajectories were also calculated for non-event days for peak-hours of the measured sulfuric acid concentration. The results are discussed in the main manuscript and presented here in Figure S5. Additionally, we implemented sea ice data for the year 2018 (Fetterer et al. 2017, updated daily) 

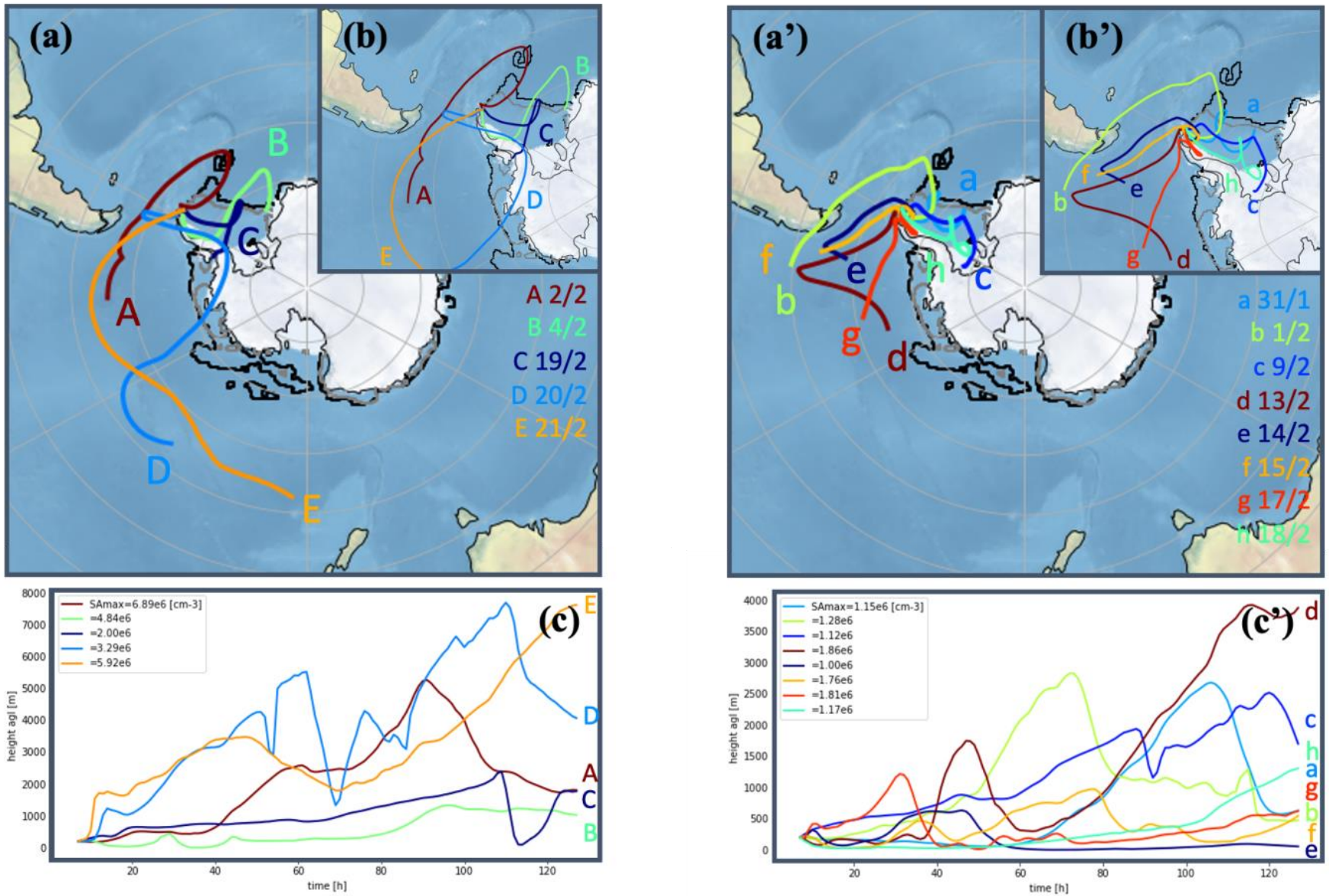

2 Figure S5: Backward trajectories calculated 120 hours for non-event days segregated by Sulfuric acid: [SA] $>2 \times 10^{6} \mathrm{molecules}^{-3}-$ left panels (a-c) and $[\mathrm{SA}]<2 \times 10^{6}$ molecules $\mathrm{cm}^{-3}$-right panels (a'-c'). In panel a-a' and b-b' the black and grey lines delimit the sea ice extent as average for January and February 2018, respectively. Sea ice data are from: ftp://sidads.colorado.edu/DATASETS/NOAA/G02135/south/monthly/ (Fetterer et al., 2017). Panel c and c' show the altitude of the trajectories and are colored according to sulfuric acid concentration (e.g., highest concentrations in darker red and lowest concentration in darker blue). The reference time for each trajectory is the time of the maximum daily SA concentration. 
Wind analysis

Joined with the back trajectories, we complemented the wind analysis with wind roses (Fig. S6) to determine possible local emission sources.
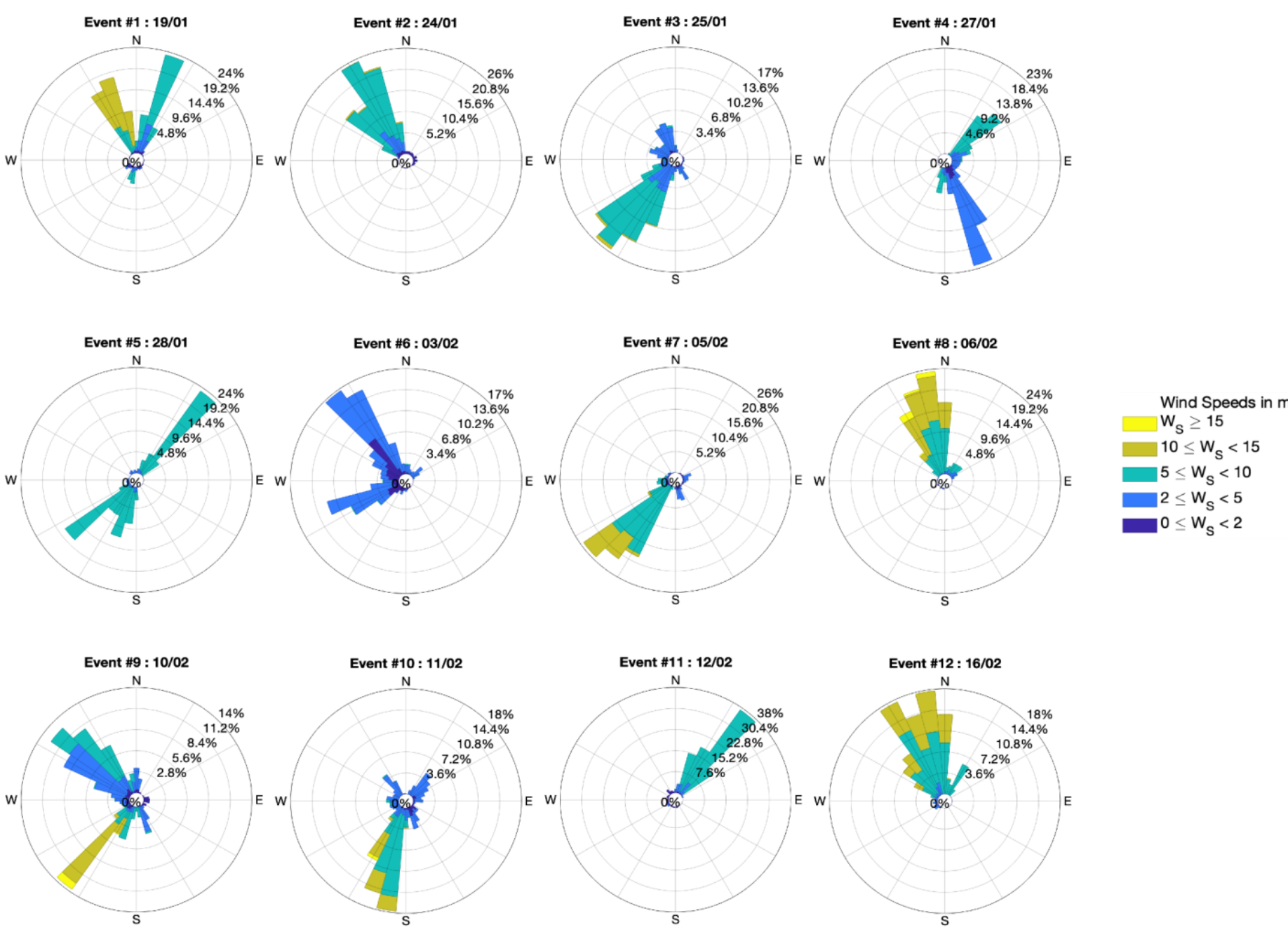

Figure S6: Winds rose for event days. The wind data of $10 \mathrm{~min}$ time resolution were accounted for every event day, separately (24h). The event numbering corresponds to the classification of the manuscript in Table 1.

\section{SI 4 Consideration for site contamination}

\section{Station activity}

Even if the laboratory container was located $800 \mathrm{~m}$ further away from the main accommodation building of the station, contamination from human activity (e.g., heating and cooking) is to be expected. Flags were assessed according to wind direction and low wind speed, and further considered in the aerosol analysis. Note that DMPS data were flagged and as possibly contaminated when wind originated from the station main building sector (i.e., $0^{\circ}-90^{\circ}$ ), during low wind speed conditions, or when a pollution event is suspected (also marked as flag number 189, 188, 599, respectively, in Table 1).

\section{Flight activity}

Being a logistic hub for the whole North Antarctic Peninsula, Marambio station airfield operates many flights, especially during the summer season. We investigated the disturbance of the flying activities and the possible contamination on our data. As visible from Figure S8, out of the 12 days where particle formation was 
observed, simultaneous air traffic was recorded only for 4 NPF days: on Jan $25^{\text {th }}$ and $27^{\text {th }}$, and on Feb $5^{\text {th }}$ and $10^{\text {th }}$. This eventually impacted our analysis and specifically the determination of the aerosol parameters such as the growth rate depending on the DMPS data, then flagged as pollution points. The small size particles were not seen to be significantly affected by flights, as suggests the resulting size series from the NAIS and the PSM (cf. Figure 2), likely due to favorable wind directions and the inlets sampling lines facing South.

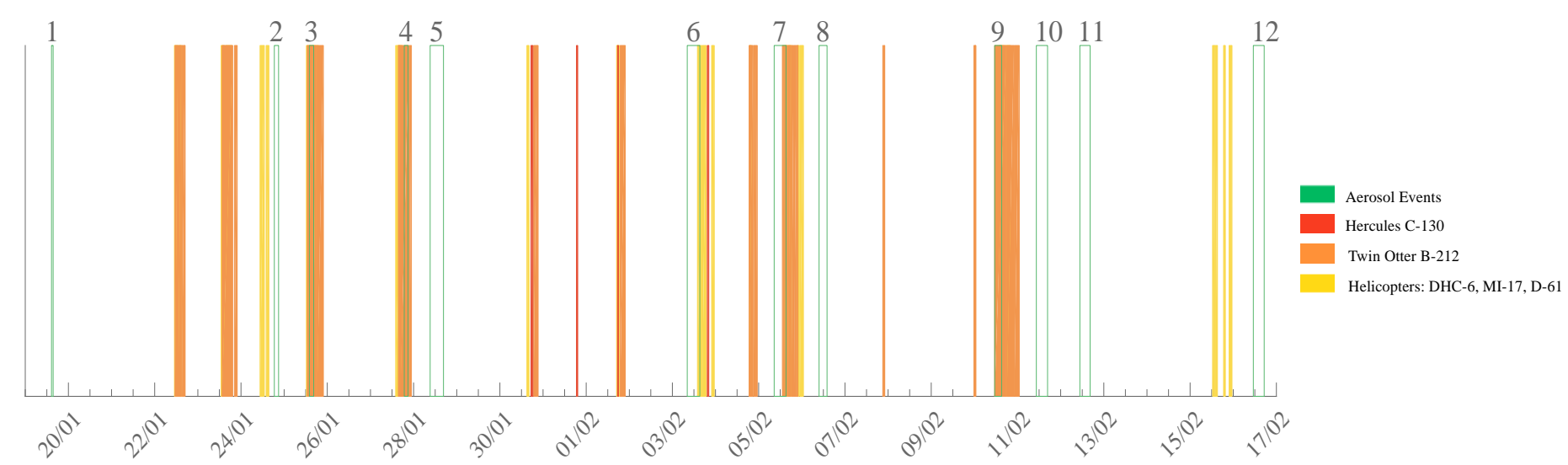

Figure S7: Time series of reported flying movements (red bars: Hercules activity, orange bars: Twin Otter activity, yellow bars: Helicopter(s) activity) in relation to observed NPF events (green bars) during the summer campaign. Numbers above the green bars inform the event number according to the aerosol characterization made in Table. 1 in the manuscript.

\section{References}

Asmi, E., Neitola, K., Teinilä, K., Rodriguez, E., Virkkula, A., Backman, J., Bloss, M., Jokela, J., Lihavainen, H., de Leeuw, G., Paatero, J., Aaltonen, V., Mei, M., Gambarte, G., Copes, G., Albertini, M., Fogwill, G. P., Ferrara, J., Barlasina, M. E., and Sánchez, R.: Primary sources control the variability of aerosol optical properties in the Antarctic Peninsula, Tellus B: Chemical and Physical Meteorology, 70, 1-16, 10.1080/16000889.2017.1414571, 2018.

Bianchi, F., Kurtén, T., Riva, M., Mohr, C., Rissanen, M. P., Roldin, P., Berndt, T., Crounse, J. D., Wennberg, P. O., Mentel, T. F., Wildt, J., Junninen, H., Jokinen, T., Kulmala, M., Worsnop, D. R., Thornton, J. A., Donahue, N., Kjaergaard, H. G., and Ehn, M.: Highly Oxygenated Organic Molecules (HOM) from Gas-Phase Autoxidation Involving Peroxy Radicals: A Key Contributor to Atmospheric Aerosol, Chemical Reviews, 119, 3472-3509, 10.1021/acs.chemrev.8b00395, 2019.

Brewer, G. P.: Minor elements in seawater, Chemical Oceanography, 1, 415-496, 1975.

Chan, T., Cai, R., Ahonen, L. R., Liu, Y., Zhou, Y., Vanhanen, J., Dada, L., Chao, Y., Liu, Y., Wang, L., Kulmala, M., and Kangasluoma, J.: Assessment of particle size magnifier inversion methods to obtain the particle size distribution from atmospheric measurements, Atmos. Meas. Tech., 13, 4885-4898, 10.5194/amt13-4885-2020, 2020.

Draxler, R. R. and Hess, G.: Description of the HYSPLIT4 modeling system, 1997.

Draxler, R. R. and Hess, G.: An overview of the HYSPLIT_4 modelling system for trajectories, Australian meteorological magazine, 47, 295-308, 1998.

Ehn, M., Thornton, J. A., Kleist, E., Sipilä, M., Junninen, H., Pullinen, I., Springer, M., Rubach, F., Tillmann, R., Lee, B., Lopez-Hilfiker, F., Andres, S., Acir, I.-H., Rissanen, M., Jokinen, T., Schobesberger, S., Kangasluoma, J., Kontkanen, J., Nieminen, T., Kurtén, T., Nielsen, L. B., Jørgensen, S., Kjaergaard, H. G., Canagaratna, M., Maso, M. D., Berndt, T., Petäjä, T., Wahner, A., Kerminen, V.-M., Kulmala, M., Worsnop, D. R., Wildt, J., and Mentel, T. F.: A large source of low-volatility secondary organic aerosol, Nature, 506, 476-479, 10.1038/nature13032, 2014. 
Eisele, F. L. and Tanner, D. J.: Measurement of the gas phase concentration of $\mathrm{H} 2 \mathrm{SO} 4$ and methane sulfonic acid and estimates of $\mathrm{H} 2 \mathrm{SO} 4$ production and loss in the atmosphere, Journal of Geophysical Research: Atmospheres, 98, 9001-9010, https://doi.org/10.1029/93JD00031, 1993.

Fetterer, F., K. Knowles, W. N. Meier, M. Savoie, and A. K. Windnagel. 2017, updated daily. Sea Ice Index, Version 3. [ ftp://sidads.colorado.edu/DATASETS/NOAA/G02135/south/monthly/]. Boulder, Colorado USA. NSIDC: National Snow and Ice Data Center, 10.7265/N5K072F8, 2021 [last access: August 5, 2021].

Jokinen, T., Sipilä, M., Junninen, H., Ehn, M., Lönn, G., Hakala, J., Petäjä, T., Mauldin Iii, R. L., Kulmala, M., and Worsnop, D. R.: Atmospheric sulphuric acid and neutral cluster measurements using CI-APi-TOF, Atmos. Chem. Phys., 12, 4117-4125, 10.5194/acp-12-4117-2012, 2012.

Junninen, H., Ehn, M., Petäjä, T., Luosujärvi, L., Kotiaho, T., Kostiainen, R., Rohner, U., Gonin, M., Fuhrer, K., Kulmala, M., and Worsnop, D. R.: A high-resolution mass spectrometer to measure atmospheric ion composition, Atmos. Meas. Tech., 3, 1039-1053, 10.5194/amt-3-1039-2010, 2010.

Kangasluoma, J., Franchin, A., Duplissy, J., Ahonen, L., Korhonen, F., Attoui, M., Mikkilä, J., Lehtipalo, K., Vanhanen, J., Kulmala, M., and Petäjä, T.: Operation of the Airmodus A11 nano Condensation Nucleus Counter at various inlet pressures and various operation temperatures, and design of a new inlet system, Atmos. Meas. Tech., 9, 2977-2988, 10.5194/amt-9-2977-2016, 2016.

Lehtipalo, K., Leppa, J., Kontkanen, J., Kangasluoma, J., Franchin, A., Wimnner, D., Schobesberger, S., Junninen, H., Petaja, T., and Sipila, M.: Methods for determining particle size distribution and growth rates between 1 and $3 \mathrm{~nm}$ using the Particle Size Magnifier, Boreal Environment Research, 2014.

Loo, B. W. and Cork, C. P.: Development of High Efficiency Virtual Impactors, Aerosol Science and Technology, 9, 167-176, 10.1080/02786828808959205, 1988.

Manninen, H. E., Mirme, S., Mirme, A., Petäjä, T., and Kulmala, M.: How to reliably detect molecular clusters and nucleation mode particles with Neutral cluster and Air Ion Spectrometer (NAIS), Atmos. Meas. Tech., 9, 3577-3605, 10.5194/amt-9-3577-2016, 2016.

Mirme, S. and Mirme, A.: The mathematical principles and design of the NAIS - a spectrometer for the measurement of cluster ion and nanometer aerosol size distributions, Atmos. Meas. Tech., 6, 1061-1071, 10.5194/amt-6-1061-2013, 2013.

Stein, A. F., Draxler, R. R., Rolph, G. D., Stunder, B. J. B., Cohen, M. D., and Ngan, F.: NOAA?s HYSPLIT Atmospheric Transport and Dispersion Modeling System, Bulletin of the American Meteorological Society, 96, 2059-2077, 10.1175/bams-d-14-00110.1, 2015.

Stolzenburg, M. R. and McMurry, P. H.: An Ultrafine Aerosol Condensation Nucleus Counter, Aerosol Science and Technology, 14, 48-65, 10.1080/02786829108959470, 1991.

Vanhanen, J., Mikkilä, J., Lehtipalo, K., Sipilä, M., Manninen, H. E., Siivola, E., Petäjä, T., and Kulmala, M.: Particle Size Magnifier for Nano-CN Detection, Aerosol Science and Technology, 45, 533-542, 10.1080/02786826.2010.547889, 2011.

Wiedensohler, A.: An approximation of the bipolar charge distribution for particles in the submicron size range, Journal of Aerosol Science, 19, 387-389, https://doi.org/10.1016/0021-8502(88)90278-9, 1988.

Wiedensohler, A., Birmili, W., Nowak, A., Sonntag, A., Weinhold, K., Merkel, M., Wehner, B., Tuch, T., Pfeifer, S., Fiebig, M., Fjäraa, A. M., Asmi, E., Sellegri, K., Depuy, R., Venzac, H., Villani, P., Laj, P., Aalto, P., Ogren, J. A., Swietlicki, E., Williams, P., Roldin, P., Quincey, P., Hüglin, C., Fierz-Schmidhauser, R., Gysel, M., Weingartner, E., Riccobono, F., Santos, S., Grüning, C., Faloon, K., Beddows, D., Harrison, R., Monahan, C., Jennings, S. G., O'Dowd, C. D., Marinoni, A., Horn, H. G., Keck, L., Jiang, J., Scheckman, J., 
1 McMurry, P. H., Deng, Z., Zhao, C. S., Moerman, M., Henzing, B., de Leeuw, G., Löschau, G., and Bastian, 2 S.: Mobility particle size spectrometers: harmonization of technical standards and data structure to facilitate 3 high quality long-term observations of atmospheric particle number size distributions, Atmos. Meas. Tech., 5, 4 657-685, 10.5194/amt-5-657-2012, 2012. 